\title{
Challenges of Total Quality in Education through Quality Assurance Principles in One Institution of Higher Education in South Africa
}

\author{
Professor Kholeka Constance Moloi
}

\author{
Vaal University of Technology, Faculty of Human Sciences, \\ Vanderbijlpark, 1900, South Africa \\ Email:conniem@vut.ac.za
}

\author{
Miss Reitumetse Rejoyce Motaung \\ Vaal University of Technology, Faculty of Human Sciences, \\ Vanderbijlpark, 1900, South Africa \\ Email: reitumetsem8@gmail.com
}

\section{Doi:10.5901/mjss.2014.v5n1p137}

\begin{abstract}
Debates about how quality education can be accessed by all students within the South African higher education environment continue to dominate in the media and academic circles as well as among policy makers and those who have a vested interest in education. Given the disparities in terms of socio-economic and political conditions inherited from the previous segregationist regime in the country, it is challenging to conceptualise how quality assurance mechanisms can be applied across all higher education institutions using the same standards, measurements and criteria. Indeed, in South Africa, social inequalities were deeply embedded and reflected in all spheres of social life, as a product of the systemic exclusion of blacks and women under colonialism and apartheid (segregation) and these inequalities continue to shape the educational landscape. The purpose of this paper is to explore how the quality of education can be improved through quality assurance mechanisms in one institution of higher education that serves the majority of students who come from underprivileged socio-economic backgrounds.
\end{abstract}

Keywords: Total quality management, Quality assurance, Higher education, Economics, Quality improvement.

\section{Introduction}

Debates about how quality education can be accessed by all students within the South African higher education environment continue to dominate in the media and academic circles, and among policy makers and those who have a vested interest in education. Given the disparities in terms of socio-economic and political conditions inherited from the previous apartheid (segregationist policy according to class, race and gender inequalities) regime in South Africa, it is challenging to conceptualise how quality assurance mechanisms can be applied across all higher education institutions using the same standards, measurements and criteria. In line with this thought, Badat (2010: 1) has argued that in South Africa, social inequalities were embedded and reflected in all spheres of social life, as a product of the systemic exclusion of blacks and women under colonialism and apartheid. The higher education system was no exception. Social, political and economic discrimination and inequalities of a class, race, gender, institutional and spatial nature profoundly shaped, and continue to shape, South African higher education. To redeem the effects of the apartheid era, South Africa's new democratic government committed itself in 1994 to transforming higher education as well as the inherited social and economic apartheid structure and institutionalising a new social order.

The new social order included, amongst others, the introduction of a quality assurance system within higher education, i.e. the standards-driven reform programme (West-Burnham, 2009: 317). Consequently, between 2001 and 2004 the Higher Education Quality Committee (HEQC) abstracted and developed the first cycle of quality assurance (Council on Higher Education 2011: 5). The CHE was tasked to oversee the quality assurance system while the HEQC was established to conduct audits of South African universities based on self-evaluation by institutions of their performance against a range of criteria and external peer assessment. The HEQC was further given the responsibility of accrediting new qualifications and courses and conducting national reviews, quality promotion and capacity development to train academics and senior managers to assist in the implementation of the national quality assurance system and 
helping institutions to prepare for their participation in quality assurance system (CHE, 2011: 5). The HEQC policy gives a definition of how higher education qualifications should be included in the National Qualification Framework (NQF), which covers all levels of education and registers all qualifications. In this regard, research by Srikanthan and Dalrymple (2002: 1) indicates that quality in higher education - how to enhance it and how to evaluate it - has been placed squarely on the contemporary agenda in higher education globally.

In our schema, the concept of quality assurance is complex in that it involves various dimensions of inputs, process and outcomes and the way these dimensions change over time. We argue that these processes are germane to the dominant hegemony of macro-economic policies that are globalising higher education in order to serve Western capitalist economies and heavily espoused by governments globally (Arshad-Ayaz, 2008: 480). While this is our argument, research by West-Burnham (2009: 320) has shown that institutions that have previously applied the principles of total quality management (TQM) have shown positive results as they adopted TQM as a reform and restructuring process. He further argues, however, referring to work conducted by Davies and West-Burnham (1997), Doherty (1994), Lomax (1996) and Parsons (1994), that there are no examples of educational institutions that have adopted and sustained a total quality approach. Thus, to derive a better understanding of quality assurance, the authors draw heavily from W. Edwards Deming's total quality management (TQM) as a theoretical framework and we also borrow from analyses by various scholars. According to West-Burnham (2009: 315), TQM combines elements of scientific management and a Zen-based belief in perfectibility, and the evolutionary process has seen the adaptation of TQM from manufacturing to service industries and from the private to the public sector. Accordingly, Harvey (2004 \& 2007), quoted in Santiago, Tremblay, Basri and Arnal (2008: 261), defines quality assurance as the process of establishing stakeholder confidence that provision (input, process and outcomes) fulfils expectations and measures up to a threshold of minimum requirements. Vroeijenstijn (1995), cited in Baijnath, Maimela \& Singh (2001: 107), describes quality assurance as a "systematic, structured and continuous attention to quality in terms of quality maintenance".

Consequently, the first cycle of quality assurance in South African higher education focused on providing an integrative foundation for the work of the HEQC in that all institutions had to adhere to the same approach and criteria for them to generate a common basis in developing a shared understanding and approach to quality. To institute this, the HEQC system applied four well-known elements of quality assurance which are: programme accreditation (to ensure provider compliance with minimum standards in order to offer learning programmes at higher education), national reviews (to focus on existing programmes in a particular area), institutional audit process (to look at the effectiveness of an institution's internal quality assurance mechanism), and quality promotion (to focus on training in quality assurance methods).

In instituting this common approach, West-Burnham (2009: 317) argues, the increasing specifity of government policies and the introduction of performance-based accountability have limited the amount of discretion available to higher education to implement quality-based approaches. He further points out that in most cases quality is defined by educational policy - and there is no example yet of a national government working to the principles of total quality. Thus, the purpose of this paper is to explore how the quality of education can be improved through quality assurance mechanisms in one institution of higher education, focusing on the three elements of quality assurance: quality, standards and relevance.

\section{Problematising Quality Issues at the Institution under Study}

The achievement of equity, effectiveness and efficiency through quality assurance within individual institutions and in the entire education system remains great a challenge that faces the higher education sector in South Africa (WestBurnham, 2009: 320). The previously segregated universities in the country had to open doors to students across all races and transform curricula to be not only more locally relevant but also geared to a knowledge-driven world (Badat, 2010: 2). These institutions were also expected to train different types of graduates needed for social development and economic growth within the country but also produce scholars that would be able to tackle South Africa's problems through research that is responsive to all society's needs (HEQC, 2013: 13).

Whilst many institutions are slowly moving towards achieving the quality assurance vision and mission to provide quality education through effective teaching, access, redress, student learning, good governance and leadership, the measurement of quality is proving to be more elusive (Hanlon, Blackbourn \& Shtayer, 2008: 47). This is so because, as poignantly stated by West-Burnham (2009:316), "the hierarchical and absolutist approach engendered reinforces the notion of quality as a non-negotiable entity, of almost metaphysical status, illuminating the perceived superiority of some universities over others". West-Burnham (2009: 320-321) further elucidates significant caveats about total quality in 
education:

- The tension between government policy-making and institutional autonomy. While by law commercial organisations can determine their management philosophy, this is not the case with educational institutions. They are subject to a wide range of external requirements which inhibit their ability to make significant choices.

- The second concern is the perceived tension between the notion of professional autonomy in teaching and the insistence in total quality theory on high degrees of consensus, acceptance of organisational goals and working in teams. This leaves aside the professional status of teachers; there is obvious tension between the corporate alignment required by total quality and the historic autonomy of teachers.

- Managerialism in the context of education is taken to mean excessive concern with the systems and structures of the core purpose of the organisation. The bureaucratic imperative is often cited as one of the main objectives to quality management strategies. Thick folders of standard operating procedures seem far from the joy of learning and the creativity of teaching.

- The appropriating of industrial models by education legitimises a form of cultural imperialism, expanding the array of western management innovations finding their way into traditional cultures.

Despite ensuing challenges with quality measurement, the National Plan for Higher Education (NPHE) stresses the importance of the role academic development has to play in improving the efficiency of the higher education system in terms of graduate output (DoE 2001:31). The institutional reputation of the university under study has for a number of years been overwhelmed by internal turmoil, blurring the line between misconduct and policy issues. This inability to distinguish between misconduct and policy issues led to many unethical practices being overlooked as rights by many stakeholders within the institution. On the other hand, the institution deals with employment equity imperatives that are counterbalanced by a lopsided employee profile, compounded by issues such as the clash of cultures, racism, disparities and the harmonisation of the institutional environment. Another challenge that affects the efficiency levels of the university is the after-effects of a casual deployment of employees into roles that they were not trained for. Not only is such misplacement demoralising, but it unconsciously breeds a culture of insufficient competencies and causalities in terms of work ethic, service delivery, input and output measures.

The authenticity of an institution will depend on whether it is perceived as an independent institution that adds value to teaching and learning accomplishments within higher education rather than as an agency in pursuit of compliance. Its independence cannot be affirmed in a vacuum but will be shaped by its interactions with a range of stakeholders and partners. In similar vein, the greater distinction of its mission indicates that producing employable graduates of top quality could also be a more focused framework for improved results. There is greater potential for achieving improvement in teaching and learning, research and community engagement through the concentration of resources and quality support on niche areas rather than thinly dispensing resources across the system. The authors argue that the quality assurance system of the institution will have to play a role in fostering education in a way that does not put quality, standards and relevance at extreme ends of the higher education spectrum of achievement.

\section{Theoretical Framework on Quality}

To provide a theoretical framework for this paper, the authors draw heavily from W. Edwards Deming's total quality management theory and other models of quality assurance. Different scholars place different emphasis on the total quality approach. For example, West-Burnham (1992) places greater stress on the values basis of management while Murgatroyd and Morgan (1992) place emphasis on the techniques of total quality management and Greenhood and Gaunt (1994) stress the importance of statistical process control (West-Burnham, 2009: 317). The components of total quality management are synthesised by West-Burnham (2009: 314-15) as follows:

- The centrality of the design process in order to ensure that the product meets customer specifications;

- The use of statistical process control to ensure compliance with specification in the manufacturing process;

- The emphasis on prevention, "right first time", rather than remediation;

- The use of analytical and problem-solving techniques by the workforce to improve process;

- Engagement with the customer to ensure continuous improvement of both product and process; and

- The creation of a team-based corporate culture with a high degree of consensus on organisational goals, purpose and process.

In their endeavours to come to terms with the concept of quality, Harvey and Green (1993), quoted by Akoojee and Nkomo (2007: 393), have identified four discrete but interrelated ways of thinking about quality which are considered 
useful in understanding the concept of quality. For Akojee and Nkomo, quality is seen firstly as "exceptional or perfection", secondly as "fitness of and for purpose", thirdly as "value for money", and fourthly as "transformation". The $\mathrm{HEQC}$ re-affirms that quality is the primary responsibility of institutions and that this responsibility involves different levels and methods of accountability which involve the state, society, students, and the community of academic peers in the different disciplines, the professions and the fields of study (CHE, 2011: 16).

In economics, there is a vast literature demonstrating the importance of human capital for economic development and the reduction of income inequality as well as a renewed concern for the need of advanced competencies to face the knowledge requirements of the new economy (Arshad-Ayaz, 2008: 485). However, there is also a more sceptical view, particularly regarding the social benefits of uncontrolled expansion of higher education (Schwartzman 2003: 179). Wolf (2002: 332) affirms that a society with better educated teachers, administrators, traders, health care and personal service providers should be a better place to live than a society without them. A country needs teachers to provide better education to children, and this is an important asset. In the long run, it seems clear that no sustained and well-balanced economic development can occur without an important pool of competent and well-educated professionals. That being said, there is a growing amount of literature which argues that the expansion of higher education worldwide is related rather to lifestyles and competition for scarce jobs than to the functional requirements of the job markets. In the absence of demands for skills, the continuous expansion of higher education may reinforce the tendency to make credentials more important than professional competence. This tendency can be costly to society, and prevent the ability of higher education institutions to develop the abilities and skills that could help to break the vicious cycle of low economic development and the shortage of well-qualified human capital (Castro and Levy, 2000: 112).

Economic theory provides widely accepted underlying principles to justify government intervention in (and public funding of) tertiary education (Santiago et al., 2008: 168). The concerns provide the rationale for government's involvement: efficiency concerns, often called the "market failures"; equity concerns, mostly related to providing equal educational opportunities for all; and effectiveness concerns, which are linked to internal systems for quality management across policies, processes and structures. Against this background, Reviews of National Policies in Education (2008: 281) reports that, as a consequence, implementation has tended thus far to depend on pilot projects financed by foreign donors, on an individual's good will at ministerial and local level, as well as on certain strategies adopted by school governing boards. Implementation has also become dependent on each school's teaching team's ability to be imaginative about making ad hoc adaptation for learners with mobility impairment, sight impairment or with other particular needs. Lack of tools and statistics allowing for policy planning and monitoring has hindered the evaluation of initiatives, in terms of their efficiency, cost effectiveness and equity.

Marock (2000: 13) defines quality as "the totality of characteristics of an entity that bears on its ability to satisfy stated and implied needs". On the other hand, Santiago et al. (2008: 262) define quality as the distance between an objective and a result, with the implicit assumption that quality improves as this distance shrinks. With reference to all these perspectives on quality, Harvey and Green (1993), quoted in Santiago et al. (2008: 262), state that the problem "is not a different perspective on the same things but, different perspectives on different things with the same label". In simple terms, what has been presented is that, in order for researchers to resolve different ways of thinking about quality, they have tried to review the abstract concept of quality and to focus on its various dimensions. The report by the Quality Committee (2008) established by the current Minister of Higher Education, Dr Blade Nzimande, epitomises the indicators of quality as equity, tolerance, multilingualism, accountability and honour (Marock 2000: 13).

According to Akojee and Nkomo (2007:392), the current form of academic development stipulated in the National Plan for Higher Education (NPHE 2001: 22) includes the extended curricula rather than supplementary support, that is, the focus on extended curricula was based on the recognition that curriculum-related approaches are critical to dealing with educational disadvantage, rather than reliance on supplementary support mechanisms. In addition it is also important to place emphasis on the need to be responsive to all students rather than only those who would not normally be admitted (i.e. it should not be directed at black students only) and to ensure that technology-driven approaches are not the preferred modus operandi for dealing with disadvantage.

Pottinger (2004: 5) observes that quality assessors are responsible for a wide range of quality assurance duties under the higher education system, focussing not only on the safeguarding of quality and standards but also on educational support and development of the different higher education institutions. Support and development is ensured through the use of team-based structures for both ongoing staff development and the organisation of student learning (West-Burnham (2009: 319). Pottinger (2004: 5) also mentions induction and training of administrators and academic staff, while West-Burnham (2009: 319) includes induction and feedback channels for students, as well as greater involvement of students and parents through satisfaction surveys and the use of such surveys to inform policy. He further 
points out that standardisation of key processes to ensure consistency and adherence to defined best practice, such as admissions procedures and programme design with students applying to further their qualifications (West-Burnham, 2009:319), are key to quality assurance.

It is evident that quality assurance is the process of checking that the standards and quality of higher education provision meet agreed expectations. There are various interpretations of what exactly constitutes acceptable quality; for example, an institution's provision should be "fit for purpose", should make effective use of resources and should offer its stakeholders value for money, but it is increasingly agreed that it is important to promote improvement of quality, not just to ensure that quality is maintained. This shifts the emphasis from quality assurance to quality enhancement (El-Khawas 1998: 4).

\section{Implementing Quality Assurance: Issues of Equity, Effectiveness and Access}

According to CHE (2011: 5), the first seven years of quality assurance have provided benefits for higher education institutions and the higher education system as a whole in South Africa. Since the conclusion of the first cycle of quality assurance between 2001 and 2004, it is important to evaluate and to use the knowledge acquired in the first accomplishments of the higher education system to conceptualise an approach that will guide the HEQC in the second leg of quality assurance during 2012 and 2017. As a result, the purpose of the second cycle of quality assurance is influenced by changes in the higher education environment in order to contribute to an overall improvement in the retention and progression of students in the higher education system.

Given the latter, one clear objective of South African education law and policy is equity. According to the education law amendment of 1997 cited in the Reviews of National Policies for Education (2008: 155) equity refers to fairness, or principles of justice, aimed at redressing inequalities in opportunity among individuals or groups. The term does not mean that everyone should be treated the same; it actually recognises that people have different needs, and that it is sometimes necessary to take unequal measures in order to overcome historical disadvantages. Concerning effectiveness, the evaluation of the quality of an institution's external engagement is dependent on a clearly articulated strategy, clearly identified communities of interest, and consensus on measurable performance indicators to be used for normative and summative evaluation of the strategy's effectiveness.

Extending this view, Bergquist (1995: 25) offers a fascinating argument suggesting that quality can be achieved through, and by means of, open and unfettered institutional access, and that real access cannot be achieved without attention being paid to quality. It can be concluded then, that quality and access issues cannot be separated if we are committed to transformation. Therefore, in our view, the objective of higher education should be to achieve the standard and work towards excellence. Premised on the view that there are important questions of "ends" that need to be considered in making judgements about quality, Akoojee and Nkomo (2007: 394) suggest that quality in South African higher education should be understood within a context of redress, equity and access, which has as its objective the transformation of society.

Given the preceding discussion, quality concerns are generally based on the values, purposes and ends of the beholder. In order to build an incorporated quality assurance process, core quality specifications or quality indicators should be identified to address issues relating to educational standards, the teaching, learning and research processes, student tuition, and the optimal infrastructure requirements. The authors concur with those who hold that quality is not a destination, but a journey towards improvement and excellence in the educative processes in higher education.

\subsection{Quality in teaching and learning}

Quality in higher education means that the educational process is such that it ensures that students achieve their goals, and thereby satisfies the needs of society and contributes to national development (Mishra 2007: 13). According to WestBurnham (2009: 317), this is problematic because the quality approach argues that a quality lesson is delivered in terms of fitness for purpose, i.e. it starts with the learner rather than an abstract view of how things should be. This tension, according to West-Burnham, reveals one of the main paradoxes in the application of the quality principles to education. Mishra (2007:13) quotes a suggestive definition of quality education by Barrow (1991: 61) as being high evaluation accorded to an educative process where it has been enhanced, not only achieving particular objectives set for the course but, in doing so, fulfilling the general educational aims of autonomy. Quality education provides the ability to participate in reasoned discourse, to engage in critical self-evaluation, and to come to a proper awareness of the ultimate contingency of all thought and action (Hoy \& McCarthy 1994: 9). In contrast to this assertion, West-Burnham (2009: 317) argues that 
in most developed countries it is possible for the wealthy to buy privileged access to education. However, a genuine choice does not exist in most education systems, while the ability to choose is usually the function of the ability to pay.

This is true of South African higher education. Those students whose parents can afford it go to some of the most privileged higher education institutions while the majority of the disadvantaged populate universities such as the one under study, where material and human resources are inadequate. For Harvey and Green (1993) there is a multidimensional matrix of quality, focusing on five key aspects, namely:

- Exception, where quality is defined in terms of excellence, passing a minimum set of standards;

- Perfection, with quality focusing on the process and aiming at zero defect;

- Fitness for purpose, where quality relates to a purpose defined by the provider;

- Value for money, where quality focuses on efficiency and effectiveness by measuring outputs against inputs; and

- Transformation, where quality conveys the notion of a qualitative change that enhances and empowers the student.

Arguably, without the constant implementation of the above, quality assurance will not be effective. It is also noted in the literature that the total quality system shows the outcomes and processes in a system of linkages and feedback loops (Pitt 2001: 3). The structures, processes, relationships and communication flow from learner through to the authority, the providers and the assessment system and, ultimately, to the learners themselves again, underlining the notion that quality is a process rather than a thing or product (West-Burnham, 2009: 317). The critical points in the quality spiral, as stated by Pitt (2001: 3), can be captured as the product or outcome (awards, achievements of standards or qualifications, accreditation), the inputs (learning provision, programmes, learning and learner resources; life or experiential learning), and the process (the quality of the learning and assessment interventions; the quality of the monitoring and auditing interactions).

\subsection{Improving access to higher education through government funding}

To improve access for all students in higher education, the state has introduced a student loan and bursary scheme, the National Financial Aid Scheme (NSFAS), which provides financial support to poor but academically deserving students to pursue their higher education ideals. However, despite the significant contribution that the state makes annually via NSFAS, in the 2008/09 financial year it was just over R1.5 billion, which is not sufficient (CHE 2011: 36). Moreover, it is reported that the recipients of NSFAS loans often drop out because the loan does not cover as many students as possible. Santiago et al. (2008: 193) that students in public institutions are being subsidised on a merit basis. Societal benefits generated by graduates of the same programme are likely to be comparable, which would in itself justify similar public subsidies - it is hard to argue that there are no externalities accruing from the education of the students who receive no public support for their tuition. In addition, it is known that academic excellence at the point of entry into tertiary education reflects prior educational opportunities, which are closely associated with the socio-economic background of the student. The authors maintain, however, that the selection criterion for NSFAS funding needs to be critically evaluated as some, if not most, of the students who apply for funding are not financially needy and as a result others, because of their financial background, struggle to obtain funds that they fairly deserve.

Access to the non-fee paying places is based in general on academic merit: entry criteria establish a ranking of candidates applying to each institution, and the best-ranked students access the available non-fee-paying places, while the places available on a fee-paying basis are given to those students who may be only marginally lower in the same ranking (Santiago et al. 2008: 193). Barr (2004: 267) argues that institutions should be free to vary their tuition fees provided there is a fee ceiling and that student support systems remove financial constraints at the time of attendance. In support of this view, he contends that fee differentiation has a number of advantages. The rationale for fee differentiation could be the level of student demand, the cost of provision, and the level of public subsidy. Economic theory predicts that fee differentiation would lead to improvements in the average quality and in price-quality ratios, and this claim seems to be supported by the data.

A number of prerequisites need to be in place for differential fees to work effectively. Students and their parents, as well as stakeholders, must have access to reliable information on study programmes, quality, tuition fees and future income prospects to make informed choices. In addition, a competitive and transparent tertiary education system together with good levels of student mobility facilitate the effectiveness of differentiated fees (Canton and Vossensteyn, 2001) quoted in (Santiago et al. 2008: 195). Curtis and Shani (2002), quoted in Santiago et al. 2008: 235) use students' perceptions to investigate the effect of taking paid employment during term-time on student's academic studies. They 
conclude that there are adverse effects on study in the form of missed lectures, and students' perceptions are that coursework grades are lower than they would have been had they not been working. However, students hold a different view when they highlight the benefits of working, which are not only monetary but include skills development and increased confidence. On considering these arguments, the author is of the view that the burden that part-time employment places on students and the effects that it might have on their capacity to learn effectively are likely to be more important in some circumstances.

We concur with Santiago et al. (2008: 314) that the quality assurance system could be applied in such a way that a minimum quality threshold would need to be demonstrated before an institution becomes eligible for public funds, while the results of ongoing assessment evaluation would subsequently be disconnected from public funding decisions. It would be preferable to limit the extent of indirect links such as financial rewards for institutional-level teaching excellence on the grounds of effectiveness. Indeed, these resources might be more useful in assisting poorly performing institutes to improve their quality, and the challenge is for policy makers to find the balance between reward mechanisms and resources directed to correcting deficiencies in poorly performing institutes.

\subsection{Applying standards to improve the quality of teaching and learning}

Teaching and learning are complex processes that are not easily amenable to reductionist and instrumental definitions (West-Burnham 2009: 320). West-Burnham (2009:319) has argued that there are problems with applying total quality to the core purpose of education - the nature of learning and teaching. He points out that it is relatively easy to apply total quality principles to administrative systems and that this has validity. This difficulty is compounded also by the conceptual differences between teaching and learning standards. Teaching standards might best be viewed as process or delivery standards. These are the aspects of institutional provision or educational delivery commonly accepted as having an effect on the quality of student learning (Tertiary Education Quality and Standards Agency (TEQSA) 2011:3).

As illustrated by the Tertiary Education Quality and Standards Agency (TEQSA 2011: 3), these aspects include curriculum design, the quality of teaching, student learning support, and the infrastructure which directly supports the processes of teaching and learning. Learning standards are best viewed as outcome standards. The learning standards describe the nature and levels of student attainment - what students and graduates know and can do. Furthermore, student attainment is known by various expressions such as learning outcomes, competencies and the like, often with significant shades of meaning. Thus learning standards apply to desired areas of knowledge and skills and the levels of attainment required for graduation and for the awarding of grades at pass level or above (James, 2003: 189).

The South African Quality Authority (SAQA) Act of 1995 defines a standard as registered statements of desired educational and training outcomes and their associated assessment criteria. The standard setting and the quality assurance functions of the SAQA and the NQF are separated yet linked. They are separated to establish the integrity of the NQF, yet linked because quality assurance influences standard setting (Pitt 2001: 2). Standards also apply through the application of accreditation criteria. There is a greater institutional awareness of the importance of meeting minimum standards for programme design, teaching and learning, programme coordination, quality of educational infrastructure, and the number and qualifications of academic staff assigned to a programme (CHE 2011: 5).

Institutions that receive provisional accreditation with conditions for their programmes are provided with a time frame to meet the required minimum standards, and these standards must be met before the programme can be offered. This reinforces the importance of ensuring minimum quality standards in relation to teaching and learning. Mishra (2007: 88) postulates that standards are formally documented requirements and specifications against which performance can be assessed. Standards as a term can be used in quality assessment in the sense of a measure of processes, performance and outcomes that can be quantified or assessed on a continuum.

Marock (2000: 30) suggests that in order to meet the quality objectives that have been set for the system, it is necessary to reach a common definition of quality. This would be the standard against which all programmes are evaluated. However, it is not enough to agree on minimum standards that represent the lowest common denominator (Marock 2000: 30). Rather, the concept of threshold needs to be deepened to ensure that the standard carries an understanding of good quality leading to applied competence. Additionally, there is an understanding that accreditation must serve to ensure that the standard of provision is good, that it should enable the individual to reach a level of applied competence and in this way protect the public and students.

This highlights the imperative of ensuring that the standard of provision is high and that accountabilities within the higher education system are engendered (Pitt 2001: 4). With regard to prior discussions, an understanding is required of the particular standards of quality that are used, and what type of pointers should be applied in order to guarantee good 
quality education and training which, in turn, ensures that proficient learners exit the higher education system. The difficulties of developing a common conception of quality have been raised by many authors. An additional issue is the specific complications that will emerge during the transitional period, while there is an absence of registered standards. Without the registered standards, the quality criteria tend to be very broad, making it difficult to gauge quality (Marock 2000: 31).

\subsection{Why is relevance of the curriculum important in quality assurance?}

Srikanthan and Dalrymple (2002: 4) argue that a cross-border provision of higher education can make a significant contribution to higher education on condition that it offers quality education, promotes academic values, and, most importantly, sustains relevance and respects the basic principles of dialogue and cooperation, mutual recognition and respect for human rights, diversity and national sovereignty. To uphold academic relevance, it is argued that the SETAs (SETA) can also help to clarify what customers want and need, thereby ensuring that various service providers have an understanding of the quality standard. Moreover, the HEQC can play a role by making sure that the quality standards address all the purposes of higher education and training, and those that are not reduced to a narrow occupational focus. This will allow for a dynamic interplay between these purposes to ensure that HET institutions are able to realise their missions (Marock 2000: 27).

The demand of relevance dates back to early insights by Cottle (1973: 1) and is anything but a transitory expression of a few misguided persons. On the contrary, it has become one of several indications of a momentous change in education. The question then becomes: how important is education for society? Relevance has operated as something of a safety valve in education systems to meet a level of demand for tertiary education far in excess of the number of places fully publicly funded without overburdening the public budget.

\section{Conclusion}

In this theoretical exposition we have learnt that quality in higher education is ensured by participation and representation of various role players in educational, social and economic structures and related processes. We have also shown that the two functions of NQF are the setting of standards and quality assurance, ensuring that quality qualifications and standards are generated and registered. It has been shown that quality assurance to attain quality education ensures service delivery of quality programmes through evaluation and monitoring mechanisms and that assessment is conducted by registered assessors and moderators. We have also shown that the HEQC plays an important role in facilitating discussions on the development of benchmarks for quality assurance criteria and processes in higher education. This implies the need to reach agreement regarding the criteria and their associated indicators to form the benchmarks against which programmes can be assessed to ensure that they are of good quality. In other words, these criteria and processes should represent the minimum threshold standard for programmes. Additional criteria may be utilised, but minimum threshold implies a standard that is acceptable to all parties, enabling them to satisfy the requirement of serving and protecting the public - the students (Marock, 2000: 28).

As far as strategies for quality assurance are concerned, we have learnt that a quality assurance policy should reflect the provider's mission and values and relate closely to the relevant strategic management plans and operations. It should set clearly measurable quality objectives at various functions and levels within the institution. The quality assurance procedures should provide opportunities for the analysis and development of the mission statement and the values and plans of the institution. Additionally, the quality assurance system should focus on how well the institution is achieving the goals derived from the mission statement. Students' attainment of intended learning outcomes should be a major consideration. Further enhancement of programme quality should also be a major policy objective. The quality assurance policy should include a commitment to the provision of adequate resources to enable the quality assurance procedures to be implemented satisfactorily.

From the discussions above, it seems that in the past, the assumption was that for each learned profession a corresponding university-level course should exist. In practice, however, these regulations work only for a few fields, such as medicine, engineering and law, whereas most higher education today tends to be general, rather than specialised. Engagement of the present day focuses on universities' application of research, and scholarship in partnership with the needs of business and communities. It can also focus on specific projects designed to generate social and economic benefits within its community of interest. In both cases, the outcomes are reflected into the modification of university programmes to ensure their continued relevance. Therefore, we can conclude that the HEQC 
should continue to use programme accreditation and national reviews as fundamental tools to ensure the quality of institutional reviews, focusing on the quality of institutional teaching and learning for student success.

\section{References}

Akoojee, S. \& Nkomo, M. (2007). Access and quality in South African higher education: the twin challenges of transformation. South African Journal of Higher Education, 21, 385-399.

Arshad-Ayaz, A. (2008). From producing citizens to producing managers: Education in a globalized world. In: Hopson R.K; Yeakey, C.C. \& Boakari, F.M. (Eds.) Advances in education in diverse communities: Research policy and praxis. Power, voice and the public good. Schooling and education in global societies, 6, (pp. 480-506) Bingley: Emerald publishing group.

Badat, S. (2010). The challenges of transformation in higher education and training institutions in South Africa. Pretoria: Development Bank of South Africa.

Baijnath, N, Maimela, S. \& Singh, P. (2001). Quality assurance in open and distance learning. (1st ed.) University of South Africa and Technikon South Africa. Tertiary Education for Knowledge Society.

Barr, N. (2001). Higher education funding. Oxford Review of Economic Policy, 20, 264-283.

Bergquist, W. B. (1995). Quality through access: Access with quality. The new imperative for higher education. New Jersey: Prentice Hall.

Castro, C. D. M. \& Levy, D. C. (2000). Myth, reality, and reform: Higher education policy in Latin America. Washington, DC: John Hopkins University Press for the IDB.

Council on Higher Education. (2011). Higher Education Quality Committee: Framework for the second cycle of quality assurance 20122017 - a consultation document. [Online] Available: www.che.ac.za (August 7, 2013)

Cottle, T. (1973). Rationale for relevance in higher education. Journal of interchange, 4, 1-15.

Davies, B. \& West-Burnham, J. (1997). Reengineering and total quality in schools. London: Pitman.

TEQSA (Tertiary Education Quality and Standards Agency). 2011. Developing a framework for teaching and learning standards in Australian higher education and the role of TEQSA. Discussion paper.

Doherty, G. (Ed.) (1994). Developing quality systems in education. London: Routledge.

El-Khwas, E. (1998). Quality assurance in higher education: Recent progress, challenges ahead. Tertiary Education and Management, 4, 1-20.

Greenhood, M.S. \& Gaunt, H.J. (1994). Total quality management for schools. London: Cassell.

Hoy, D.C. \& McCarthy, T. (1994). Critical theory. Oxford, UK: Blackwell.

James, R. (2003). Academic Standards and the Assessment of Student Learning: Some current issues in Australian higher education. Tertiary Education and Management, 9, 187-198.

Lomax, P. (1996). Quality management in education. London: Routledge.

Marock, C. (2000). Quality assurance in higher education: the role and approach of professional bodies and SETAs to quality assurance. Journal of higher education, 2, 1-86.

Mishra, S. 2007. Quality assurance in higher education: an introduction. [Online]. Available: http://dspace.col.org/bitstream/ 123456789/129/1/QAHE_Intro.pdf (August 2, 2013)

Murgatroyd, S. \& Morgan, C. (1992). Total quality management and the school. Buckingham: Open University Press.

OECD. (2008). Reviews of National Policies for Education - South Africa. [Online] Available: http://www.oecd.org/southafrica Ireviewsofnationalpoliciesforeducation-southafrica.htm (February 14, 2013)

Parsons, C. (Ed.) (1994). Quality improvement in education. London: David Fulton.

Pitt, J. H. (2001). Quality assurance in education and planning in the South African context. [Online] Available: http://www.edutel.co.za/uganda/pdfs/JPitt.pdf (August 2, 2013)

Pottinger, D. (2004). The challenge of quality assurance in global education markets. British Council Going Global Conference, Edinburgh

Santiago, P. Tremblay, E. B. \& Arnal, E. (2008). Organisation for Economic Co-operation and Development. OECD Publishing.

Schwartzman ,S. (2003). Equity, quality and relevance in higher education in Brazil. Journal of education, 76, 173-188.

Srikanthan, G. \& Dairymple, J. (2002). Developing a holistic model for quality in higher education. Planning for Higher Education, 28, 17.

Strydom, A. H. (2001). Critical perspectives on quality assurance in higher education in South Africa. [online]. Available: http://chet.org.za/files/STRYDOM\%20P\%202001\%20Quality\%20assurance\%20in\%20SA\%20HE.pdf (August 10, 2013)

West-Burnham, J. (1992). Managing quality in schools. Harlow: Longman.

West-Burnham, J. (2009). Understanding quality. In T. Bush \& L. Bell (Eds.). The principles and practice of educational management. London: SAGE.

Wolf, A. 2002. Does education matter? Myths about education and economic growth. London: Penguin. 
